LBL-36768

UC-404

\title{
Mechanical Properties of Amorphous Hard Carbon Films Prepared by Cathodic ARC Deposition
}

\author{
Simone Anders, * André Anders, * Joel W. Ager III, * Zhi Wang,* \\ George M. Pharr, ${ }^{\dagger}$ Ting Y. Tsui, ${ }^{\dagger}$ Ian G. Brown, ${ }^{*}$ and C. Singh Bhatia ${ }^{\ddagger}$ \\ *Accelerator and Fusion Research Division \\ Lawrence Berkeley Laboratory \\ University of California \\ Berkeley, CA 94720 \\ †epartment of Materials Science \\ Rice University \\ Houston, TX 77251-1892 \\ $\ddagger \mathrm{SSD} / \mathrm{IBM}$ \\ 5600 Cottle Road \\ San Jose, CA 95193
}

April 1995

This work was supported by the Electric Power Research Institute under Award Number 8042-03, the U.S. Department of Energy, Division of Advanced Energy Projects, under Contract No. DE-AC03-76SF00098; by the Center for Excellence in Synthesis and Processing-Processing for Surface Hardness, Basic Energy Sciences, U.S. Department of Energy; by the Advanced Research Projects Agency as a part of the National Storge Industry Consortium program in Ultra High Density Recording; and by the Division of Materials Sciences, U.S. Department of Energy, under Contract No. DE-AC05-84OR21400 with Martin Marietta Energy Systems, Inc., and through the SHaRE program under Contract No. DE-AC05-76OR00033 with the Oak Ridge Institute for Science and Education. 


\section{DISCLAIMER}

This report was prepared as an account of work sponsored by an agency of the United States Government. Neither the United States Government nor any agency thereof, nor any of their employees, make any warranty, express or implied, or assumes any legal liability or responsibility for the accuracy, completeness, or usefulness of any information, apparatus, product, or process disclosed, or represents that its use would not infringe privately owned rights. Reference herein to any specific commercial product, process, or service by trade name, trademark, manufacturer, or otherwise does not necessarily constitute or imply its endorsement, recommendation, or favoring by the United States Government or any agency thereof. The views and opinions of authors expressed herein do not necessarily state or reflect those of the United States Government or any agency thereof. 


\section{DISCLAIMER}

Portions of this document may be illegible in electronic image products. Images are produced from the best available original document. 


\title{
MECHANICAL PROPERTIES OF AMORPHOUS HARD CARBON FILMS PREPARED BY CATHODIC ARC DEPOSITION
}

\author{
SIMONE ANDERS*, ANDRÉ ANDERS*, JOEL W. AGER* III, ZHI WANG*, \\ GEORGE M. PHARR ${ }^{* *}$, TING Y. TSUI**, IAN G. BROWN*, AND C. SINGH BHATIA*** \\ ${ }^{*}$ Lawrence Berkeley Laboratory, 1 Cyclotron Road, Berkeley, CA 94720 \\ ${ }^{* *}$ Department of Materials Science, Rice University, Houston, TX 77251-1892 \\ *** SSD/IBM, 5600 Cottle Road, San Jose, CA 95193
}

\section{ABSTRACT}

Cathodic arc deposition combined with macroparticle filtering of the plasma is an efficient and versatile method for the deposition of amorphous hard carbon films of high quality. The film properties can be tailored over a broad range by varying the energy of the carbon ions incident upon the substrate and upon the growing film by applying a pulsed bias technique. By varying the bias voltage during the deposition process specific properties of the interface, bulk film and top surface layer can be obtained. We report on nanoindentation and transmission electron microscopy studies as well as stress measurements of cathodic-arc amorphous hard carbon films deposited with varied bias voltage. The investigations were performed on multilayers consisting of alternating hard and soft amorphous carbon.

\section{INTRODUCTION}

Cathodic arc deposition is an emerging technology for the deposition of amorphous hard carbon films [1-7]. It has the advantage of a high deposition rate combined with the feasibility of large area deposition. Magnetic filtering of the arc plasma removes macroparticles which are produced at the cathode spots along with the plasma, and thus guarantees a high film quality $[8,9]$. Amorphous hard carbon films formed by cathodic arc deposition are hydrogen-free and exhibit excellent mechanical properties such as high hardness, high mass density, and low coefficient of friction [1-7]. Applying a pulsed bias to the substrate is an easy and flexible means of modifying the energy of the incident carbon ions. The film properties such as mass density, hardness, coefficient of friction, intrinsic film stress, and elastic modulus depend strongly on the ion energy $[1,5,6,10,11]$. The quality of the film-substrate interface and the adhesion of the film can also be strongly influenced by the ion energy. The ion energy can be varied during the film deposition process in order to combine optimized interface qualities and desired film properties [12].

We have found in earlier experiments $[6,11,12]$ that a pulsed bias voltage of $-100 \mathrm{~V}$ leads to the hardest films with the highest mass density and the highest stress. At a high bias voltage of $-2 \mathrm{kV}$ the films were softer and exhibited a much lower mass density and intrinsic compressive stress. High bias causes a deep intermixing between substrate and film and leads to superior adhesion of the films.

In the present paper we report on mechanical properties of cathodic-arc deposited hard carbon films which were formed at various bias voltages. In particular, we have formed multilayers of alternating hard and soft amorphous carbon films by varying the bias voltage during deposition. "Soft" in this case means films with hardness in the range of 15-25 GPa [6] which is much smaller than the maximum hardness of $60 \mathrm{GPa}$ [12] that can be obtained for films deposited by this method but is still very hard in comparison to other thin films. The multilayers have been investigated by transmission electron microscopy and nanoindentation. Stress measurements have been performed also. 


\section{DEPOSITION OF HARD CARBON FILMS}

A cathodic arc plasma source consisting of a $6 \mathrm{~mm}$ diameter graphite cathode and a cylindrical anode was used for the formation of the carbon plasma. The discharge current was $300 \mathrm{~A}$, the source was operated in a pulsed mode with a pulse duration of $5 \mathrm{~ms}$ and a repetition rate of $2 \mathrm{~Hz}$. The source was connected to a $90^{\circ}$ bent magnetic macroparticle filter. The plasma source and filter are described in detail in $[8,9]$. The samples were mounted on a water-cooled sample holder keeping the sample at room temperature during the deposition. A negative pulsed bias voltage was applied to the sample with a pulse duration of $2 \mu \mathrm{s}$ and a pulse off-time of $6 \mu \mathrm{s}$. The bias voltage was in the range between 0 and $-2 \mathrm{kV}$. The film thickness was measured by an oscillating quartz crystal thickness monitor. The base pressure was $10^{-4} \mathrm{~Pa}$.

Three different multilayer structures have been deposited. All three structures consisted of 8 layers; the first layer at the substrate interface was a soft layer deposited at $-2 \mathrm{kV}$ pulsed bias, and the top layer was a hard layer deposited at $-100 \mathrm{~V}$ pulsed bias. The ratio between the amount of carbon deposited at high and low bias was varied for the three structures. For the first structure the ratio was $50 \%$ soft phase $/ 50 \%$ hard phase, for the second structure it was $10 \%$ soft phase $/ 90 \%$ hard phase, and for the third structure it was $90 \%$ soft phase $/ 10 \%$ hard phase. The total thickness of the multilayer structures was $250 \mathrm{~nm}$. For comparison, films were deposited at high bias and low bias voltage only with the same total film thickness of $250 \mathrm{~nm}$. Fig. 1 shows a simulation of the deposition for the $50 \%$ soft phase/50\% hard phase structure using the code T-DYN 4.0 [13].

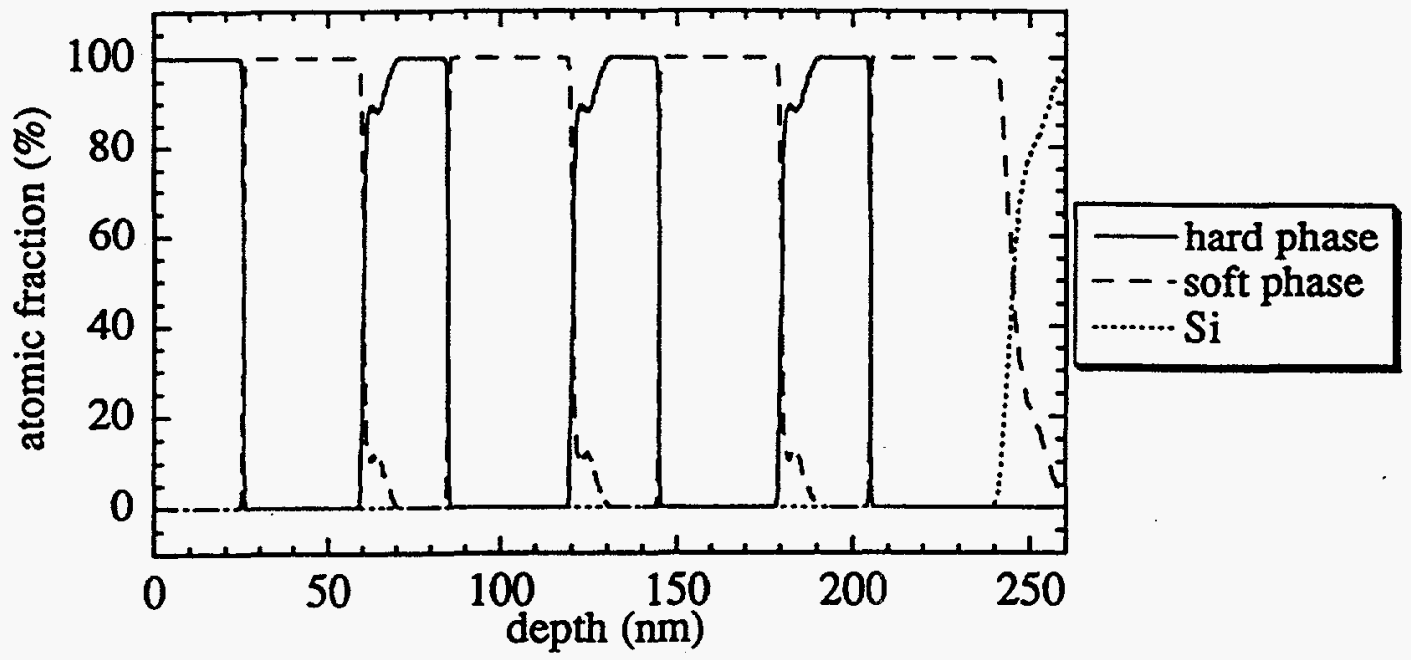

Fig. 1: Simulation of multilayer deposition for $50 \%$ soft phase/50\% hard phase structure using the code T-DYN 4.0

Since the mass density of the soft $\left(2.15 \mathrm{~g} / \mathrm{cm}^{3}\right)$ and hard $\left(3.0 \mathrm{~g} / \mathrm{cm}^{3}\right)$ phases are different, the layer thickness is $25 \mathrm{~nm}$ for the hard phase and $35 \mathrm{~nm}$ for the soft phase. The soft phase shows a considerable intermixing with the underlying layers (Si or hard phase carbon) due to the high energy of the ions during the deposition whereas the hard phase shows only very small intermixing because the ion energy is low.

\section{NANOINDENTATION}

The multilayer structures were investigated using nanoindentation techniques [14] to determine the hardness and elastic modulus. The measurements were performed using a sharp Berkovich diamond indenter. Figs. 2 and 3 show the hardness and elastic modulus of the multilayer structures as a function of the indentation contact depth. 


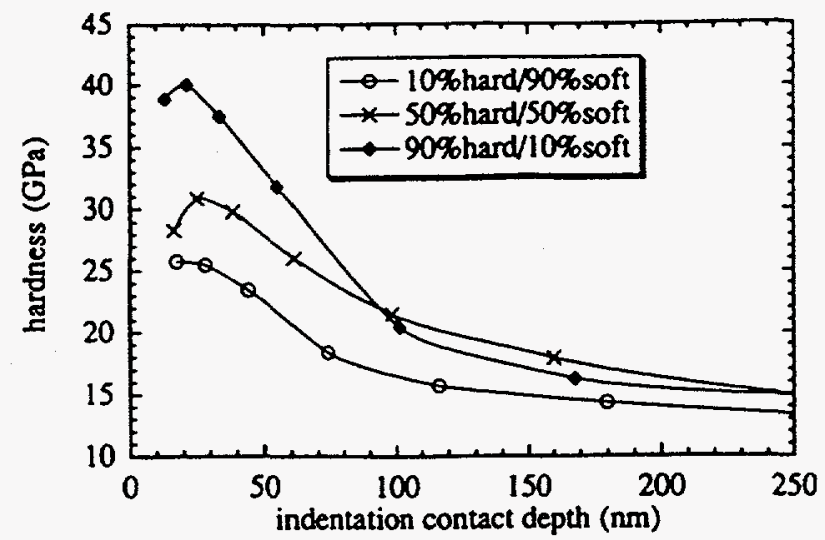

Fig. 2 Nanoindentation measurement of hardness as a function of indentation contact depth for multilayer structures of hard and soft phases of amorphous carbon on silicon. Total structure thickness $250 \mathrm{~nm}$.

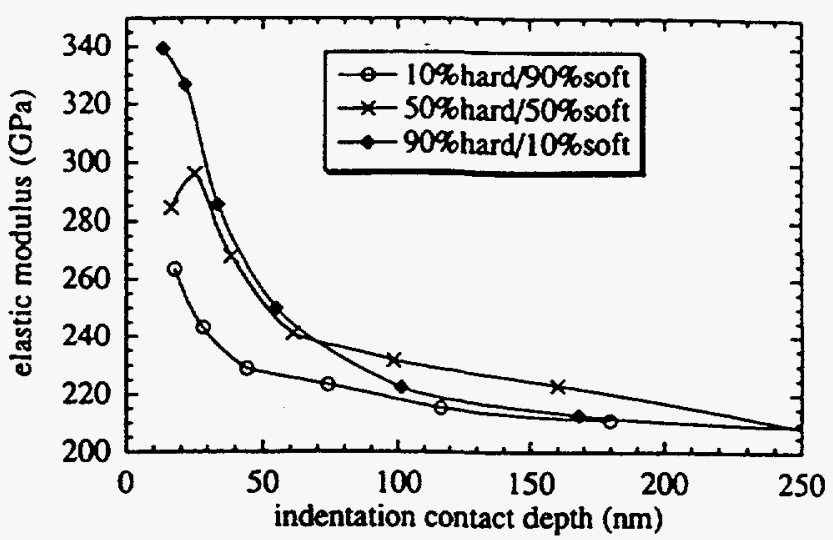

Fig. 3 Nanoindentation measurement of elastic modulus as a function of indentation contact depth for multilayer structures of hard and soft phases of amorphous carbon on silicon. Total structure thickness $250 \mathrm{~nm}$.

For all structures the hardness and elastic modulus tend to the values for the silicon substrate at large contact depths. The values at small depth are more representative for the carbon multilayer structure. The hardness and elastic modulus are greater for structures with a higher ratio of thickness of the hard phase to thickness of the soft phase.

It is of interest to compare the hardness and elastic modulus of the multilayer structures with the properties of single layers deposited only at low or only at high bias. Figs. 4 and 5 show the peak hardness and peak elastic modulus of single layers of the same thickness as the total thickness of the multilayer structures. They demonstrate that the values for hardness and elastic modulus are almost a linear interpolation of the ratio of the hard and soft phases.

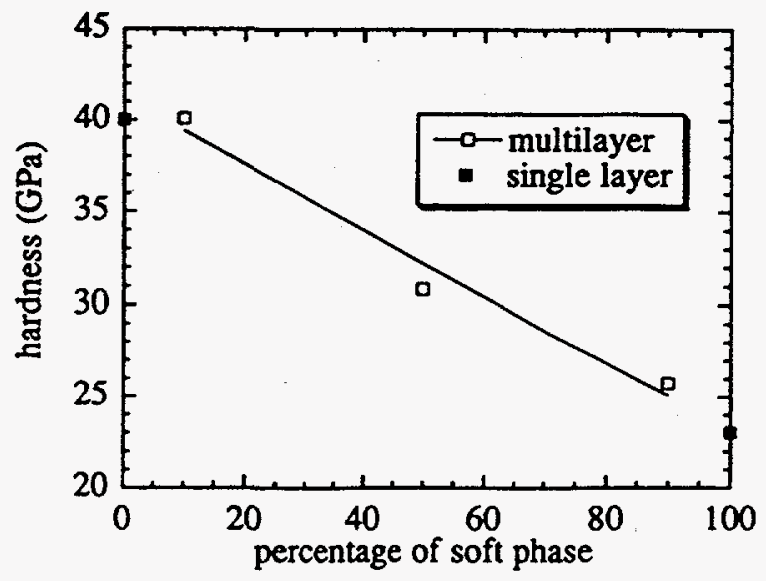

Fig. 4 Peak hardness of single layers of soft and hard carbon in comparison to multilayer structures containing soft and hard carbon layers in different thickness ratios.

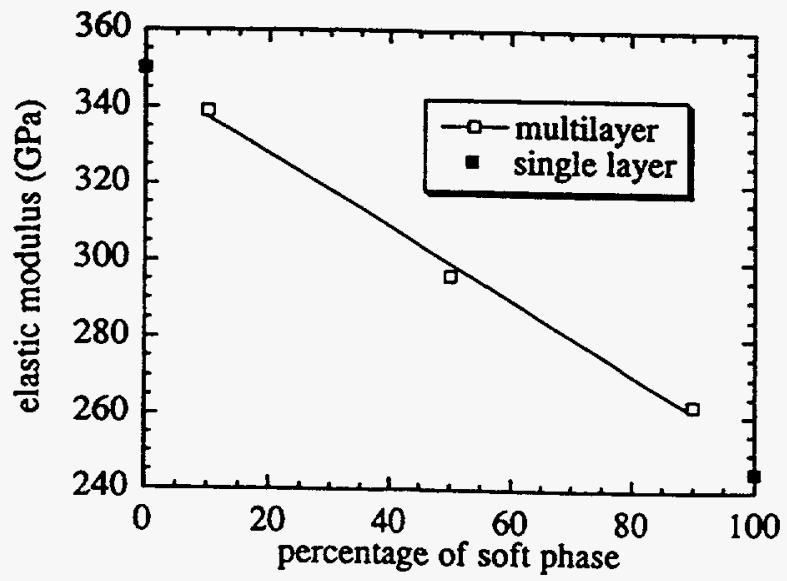

Fig. 5 Peak elastic modulus of single layers of soft and hard carbon in comparison to multilayer structures containing soft and hard carbon layers in different thickness ratios. 


\section{TKANSMISSION ELECTRON MICROSCOPY STUDIES}

The multilayer structure which contained soft and hard layers of equal amounts of carbon was examined by transmission electron microscopy (TEM) using a JEOL 200 CX microscope. Fig. 6 is a cross-section image of the structure. In the upper left corner the silicon substrate is visible, on the lower right corner the glue for the sample preparation. The first dark layer at the silicon-carbon interface is probably an amorphous, atomically mixed layer containing both silicon and carbon. The light layers are phases of soft carbon whereas the dark layers are phases of hard carbon. The multilayer structure of four pairs of layers is clearly visible.

The difference in the thickness of the soft and hard layers is due to the different densities of the layers. Measurements of the mass density of soft and hard single layers determined by electron energy loss spectroscopy (EELS) [12] and by Rutherford backscattering spectroscopy and profilometry [6] result in densities of $2.1-2.2 \mathrm{~g} / \mathrm{cm}^{3}$ and $2.8-3.0 \mathrm{~g} / \mathrm{cm}^{3}$, respectively. This large difference is probably the reason for the difference in the contrast of soft and hard layers in the TEM image. The simulation (Fig. 1) predicts a ratio between the thickness of the soft to the hard layer of 1.4 based on the ratio of the densities. The TEM picture shows a ratio of almost 2 ; this might be due to the additional effect of intermixing and possible softening of the hard layers by ion bombardment during deposition of the following soft layer. This is supported by the fact that the top hard layer is thicker than all other hard layers inside the structure.

Fig. 7 is a cross-section image with higher magnification showing on the right hand side the silicon substrate with the corresponding electron diffraction pattern for a (112) orientation. The insert on the left side is the electron diffraction pattern for the carbon film indicating an amorphous structure.

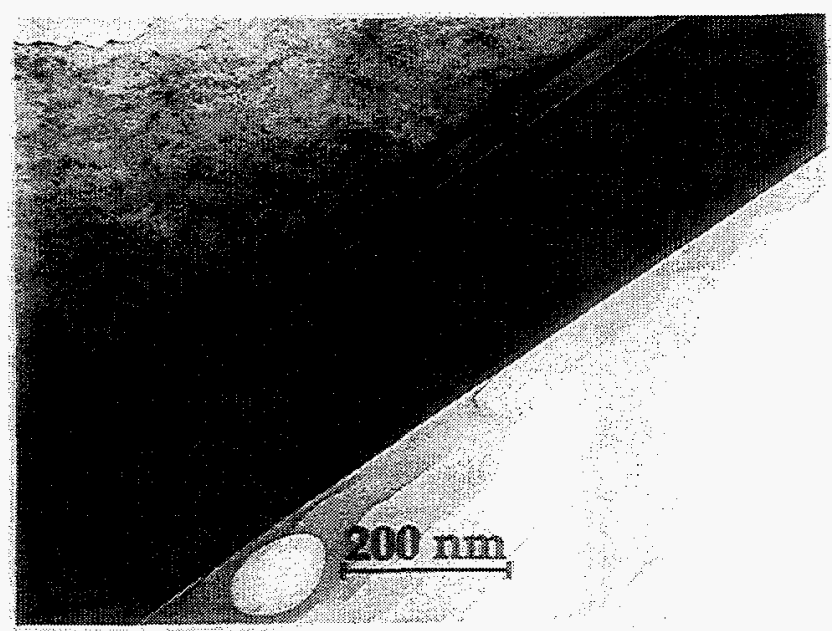

Fig. 6 TEM cross-section image of hard phase/soft phase amorphous carbon multilayer on silicon. Top left - silicon substrate, bottom right - glue for sample preparation.

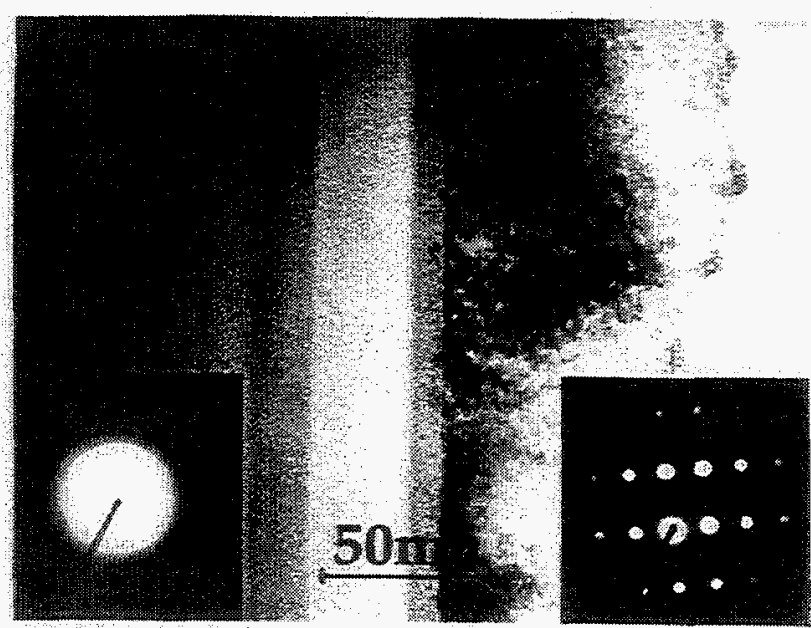

Fig. 7 TEM cross-section image of multilayer. Insert left - electron diffraction pattern of carbon material. Insert rightelectron diffraction pattern of $\mathrm{Si}$ substrate.

\section{STRESS MEASUREMENTS}

Multilayer structures as described above were deposited on $200 \mu \mathrm{m}$ thin Si wafers with a diameter of $25 \mathrm{~mm}$. The substrate curvature was measured over the central $10 \mathrm{~mm}$ of the wafers before and after deposition using a profilometer of the stylus type. The film stress was calculated with the Stoney equation [15]. For comparison the stress of single layers deposited with high bias or low bias only was also determined. Fig. 8 shows that, in contrast to hardness and elastic 
modulus, the stress is not an interpolation between the data for high and low bias only, but is considerably reduced for the multilayer in comparison to single layers.

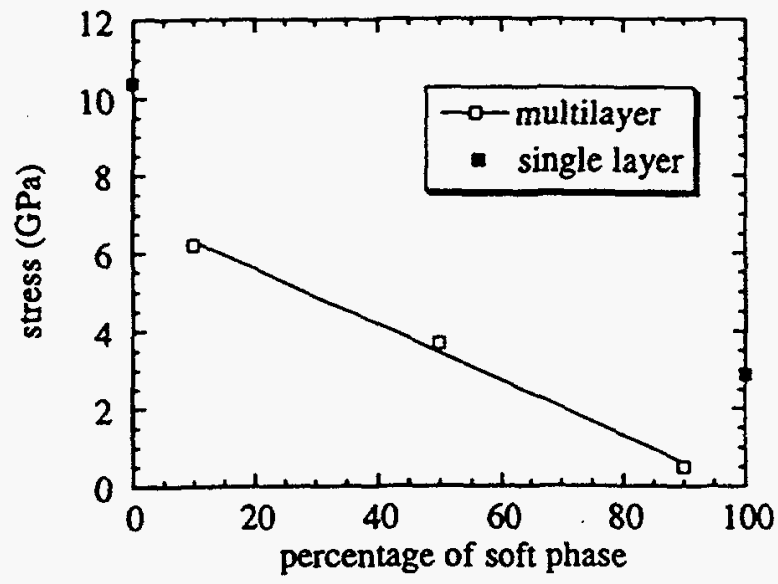

Fig. 8 Stress of single layers of soft and hard carbon in comparison to multilayer structures containing soft and hard carbon layers in different thickness ratios.

\section{DISCUSSION AND CONCLUSIONS}

It is possible to form multilayer structures containing alternating layers of soft and hard amorphous carbon by varying the pulsed bias voltage applied to the substrate during cathodic arc deposition. A computer simulation of the deposition process shows that during the deposition of a soft layer on a hard layer intermixing occurs due to the high energy of the carbon ions necessary for forming a soft layer by cathodic arc deposition. For obtaining multilayers with welldistinguished layers this limits the possible single layer thickness to a minimum of about $10 \mathrm{~nm}$.

The mechanical properties of the multilayers such as hardness and elastic modulus were found to be a linear interpolation between the properties of single layers of the same thickness as the multilayer structure. This might not be the case for all multilayer structures; it is possible that the hardness can even be increased by forming multilayers [16-18] with a larger number of layers than has been investigated in this paper. It is very interesting to note that in contrast to hardness and elastic modulus the stress is not a linear interpolation between single layer properties but is considerably lower. It can be expected that the stress can be further reduced by reducing the layer thickness and increasing the number of layers in the structure. This gives the opportunity of changing to a certain degree independently the hardness and stress in the structure. It has been reported for hydrogen-free and hydrogenated amorphous carbon films $[1,5,19,20]$ that hardness (fraction of $\mathrm{sp}^{3}$ bonds) and stress are directly correlated, and models have been developed describing the formation of $\mathrm{sp}^{3}$ bonds as stress-induced [21]. The stress in very hard amorphous carbon films can reach high values, larger than $10 \mathrm{GPa}$ [11]. Reducing the stress and containing the hardness at the same time was possible only by introducing additional chemical elements in the films as has been described for nitrogen incorporation [22]. The formation of multilayers offers an interesting alternative. It is also possible to deposit amorphous hard carbon films with a gradually varying bias voltage and to tailor in this way the film properties throughout the film the during the growth. 


\section{ACKNOWLEDGMENTS}

This work was supported by the Electric Power Research Institute under Award number 8042-03, the U.S. Department of Energy, Division of Advanced Energy Projects, under contract No. DE-AC03-76SF00098; by the Center for Excellence in Synthesis and Processing Processing for Surface Hardness, Basic Energy Sciences, U.S. Department of Energy; by the Advanced Research Projects Agency as a part of the National Storage Industry Consortium program in Ultra High Density Recording; and by the Division of Materials Sciences, U.S. Department of Energy, under contract DE-AC05-84OR21400 with Martin Marietta Energy Systems, Inc., and through the SHaRE program under contract DE-AC05-76OR00033 with the Oak Ridge Institute for Science and Education.

\section{REFERENCES}

[1] D. R. McKenzie, D. Muller, B. A. Pailthorpe, Z. H. Wang, E. Kravtchinskaia, D. Segal, P. B. Lukins, P. J. Martin, G. Amaratunga, P. H. Gaskell, and A. Saeed, Diamond Relat. Mater. 1, 51 (1991).

[2] I. I. Aksenov and V. E. Strel'nitskii, Surf. Coat. Technol. 47, 98 (1991).

[3] S. Falabella, D. B. Boercker, and D. M. Sanders, Thin Solid Films 236, 82 (1993).

[4] R. Lossy, D. L. Pappas, R. A. Roy, J. J. Cuomo, and V. M. Sura, Appl. Phys. Lett. 61, 171 (1992).

[5] P. J. Fallon, V. S. Veerasamy, C. A. Davis, J. Robertson, G. A. J. Amaratunga, W. I. Milne, and J. Koskinen, Phys. Rev. B 48, 4777 (1993).

[6] S. Anders, A. Anders, I. G. Brown, B. Wei, K. Komvopoulos, J. W. Ager III, and K. M. Yu, Surf. Coat. Technol. 68/69, 388 (1994).

[7] B. F. Coll, P. Sathrum, R. Aharonov, and M. A. Tamor, Thin Solid Films 209, 165 (1992).

[8] S. Anders, A. Anders, and I. G. Brown, J. Appl. Phys. 74, 4239 (1993).

[9] A. Anders, S. Anders, and I. G. Brown, Plasma Sources Sci. Technol. 4, 1 (1995).

[10] J. J. Cuomo, D. L. Pappas, J. Bruley, J. P. Doyle, and K. L. Saenger, J. Appl. Phys. 70, 1706 (1991).

[11] J. W. Ager III, S. Anders, A. Anders, and I. G. Brown, "Effect of Intrinsic Growth Stress on the Raman Spectra of Vacuum-arc-deposited Amorphous Carbon Films," Appl. Phys. Lett., to be published.

[12] G. M. Pharr, D. L. Callahan, S. D. McAdams, T. Y. Tsui, S. Anders, A. Anders, J. W. Ager III, and I. G. Brown, "Mechanical Properties and Structure of Very Hard Carbon Films Produced by Cathodic Arc Deposition," submitted to Appl. Phys. Lett.

[13] J. P. Biersack, S. Berg, and C. Nender, Nucl. Instrum. Methods Phys. Res. B 59/60, 21 (1991).

[14] W. C. Oliver and G. M. Pharr, J. Mater Res. 7, 1564 (1992).

[15] H. Windischman, G. F. Epps, Y. Cong, and R. W. Collins, J. Appl. Phys. 69, 2231 (1991).

[16] T. C. Chou, T. G. Nieh, T. Y. Tsui, G. M. Pharr, and W. C. Oliver, J. Mater. Res. 7, 2765 (1992).

[17] R. C. Cammarata, T. E. Schlesinger, C. Kim, S. B. Qadri, and A. S. Edelstein, Appl. Phys. Lett. 56, 1862 (1990).

[18] M. R. Scanlon, R. C. Cammarata, D. J. Keavney, J. W. Freeland, J. C. Walker, and C. Hayzelden, Appl. Phys. Lett. 66, 46 (1995).

[19] M. A. Tamor, W. C. Vassel, and K. R. Carduner, Appl. Phys. Lett. 58, 592 (1991).

[20] M. A. Tamor and W. C. Vassel, "Raman "Fingerprinting" of Amorphous Carbon Films," J. Appl. Phys., to be published.

[21] D. R. McKenzie, D. Muller, and B. A. Pailthorpe, Phys. Rev. Lett. B 67, 773 (1991).

[22] D. F. Franceschini, C. A. Achete, and F. L. Freire, Jr., Appl. Phys. Lett. 60, 3229 (1992). 